\title{
An Interdisciplinary Partnership Approach to Improving the Digital Literacy Skills of Nursing Students to Become Digitally Fluent, Work-Ready Graduates
}

\author{
Zerina LOKMIC-TOMKINS ${ }^{\mathrm{a}, \mathrm{b}, 1}$, Lindy COCHRANE ${ }^{\mathrm{c}}$, \\ Tania CELESTE ${ }^{\mathrm{c}}$ and Morag BURNIE ${ }^{\mathrm{d}}$ \\ ${ }^{a}$ Department of Nursing, The University of Melbourne, Australia \\ ${ }^{\mathrm{b}}$ Centre for Digital Transformation of Health, The University of Melbourne, Australia \\ ${ }^{\mathrm{c}}$ Library Services, The University of Melbourne, Australia \\ d Academic Skills Unit, The University of Melbourne, Australia
}

\begin{abstract}
Digital transformation and the development of a digitally fluent nursing workforce are necessary for engagement with digital technologies in healthcare settings. For this purpose, educators aim to develop workforce-ready graduates equipped with disciplinary knowledge, expertise, and digital capabilities supportive of further professional development. Having identified a subset of nursing students with low levels of digital literacy, the nursing faculty engaged with library services and the academic skills unit to develop and embed a sustainable Nursing Digital Literacy Module in the graduate entry to practice nursing program. This paper reports on the model created and early evaluation of the student uptake of the module.
\end{abstract}

Keywords. Digital literacy, digital health, nursing students, education, workforce, library

\section{Introduction}

The implementation of digital health technologies into healthcare environments depends on the agility of the healthcare workforce to adapt, use, and effectively contribute to the development of these innovations. Unfortunately, literature suggests that some nursing students have low levels of digital literacy [1], which was incidentally observed at this university. Following identification of a small cohort of first year graduate entry to practice Master's nursing students, possessing low digital literacy skills to manage their studies and assessments related to the course and work-integrated learning environments (WIL), nursing academics recognized that a significant intervention was required to address digital literacy in this population. Without this intervention, this student population was unlikely to successfully meet their course requirements. Addressing deficits in digital literacy is important as students were likely to carry low levels of digital literacy into their nursing practice thus potentially having a negative impact on patient

\footnotetext{
${ }^{1}$ Corresponding Author, Zerina Lokmic-Tomkins, Department of Nursing, The University of Melbourne, Grattan Str, Melbourne, Australia; E-mail: lokmicz@unimelb.edu.au.
} 
outcomes [1]. To address the issue, the academic nursing team reached out to the discipline-specific librarian to identify a diagnostic tool that could help identify gaps in basic digital literacy skills to be addressed through purposeful intervention. The team aimed to build a long-term, sustainable partnership and create a digital literacy module embedded in a learning management system (LMS) for easy access to students. This paper describes the results of this partnership.

\section{Methods}

\subsection{Development of the Module Brief}

Initial planning for the brief comprised the nursing program director, two staff members from the academic skills unit, the digital capabilities project coordinator, discipline librarian and two liaison librarians. The initial discussions focused on the needs of students to meet course requirements and WIL. The planning evolved towards the need to prepare nursing students with digital skills required to meet the demands of digitallydriven healthcare environments. The assumption was made that the module content must meet the needs of the students whose digital literacy was lowest whilst containing elements engaging to students whose level of digital literacy was higher. The module had to be scaffolded so that the complexity of digital literacy could be expanded as the complexity of the course and WIL environments grew. Students could access the module as needed. Through reiterative discussion, the team decided that the module should contain seven themes: Theme 1: Digital skills required to use LMS, including WIL systems; Theme 2: Basic Computer Skills; Theme 3: Internet Basics; Theme 4: Using Email; Theme 5: Microsoft Word. Theme 6: Microsoft PowerPoint.; Theme 7: Using Library to improve information literacy skills. These themes provided the anchor where there was a danger of being overwhelmed on what to include in each module.

\subsection{Screening Tools}

The team explored existing generic diagnostic tools and resources such as a) the Digital Competence Wheel' [2], b) E-health Literacy Assessment Toolkit [3], and c) 'All Aboard' [4] as means to allow students to self-identify deficits in digital literacy. When discussing the tools, the guiding principle was that the tool would be adaptive to the needs of the discipline and help identify students who needed more significant support and referral to further resources.

\subsection{Module Composition}

The module was developed to assist students to build digital literacy skills essential for full engagement with their nursing studies and WIL. As the students are time-poor, the module was designed to be worked through as a series of steps, to work at their own pace. Using existing resources that were freely accessible to the university and internally available resources, the librarians curated these resources utilizing the brief to create a module that incorporated the diagnostic tools and the learning resources needed to address self-identified deficits. The need for the resources to be freely available, of good quality and reliable, was imperative due to the need to facilitate the long-term 
sustainability of the module utilization without causing undue constraints on the operating budget to any of the partners involved. In addition, it was reasoned that with free resources, this model could be transferred to any setting where there was a need to improve future workforce digital literacy skills.

For each of the seven themes (see section 2.1), the student had an option to selfassess their skill level on a chosen topic before commencing the module, record their results using a poll for each skill, and undertake online training to learn new digital literacy skills by clicking on the links suggested. After that, the student could undertake the same assessment to determine if there was an improvement in their skill. In Theme 1, students could watch a series of videos that provided an overview of the LMS, navigate to different areas of the course, navigate the assessment tab, view lists of assignments, and submit the assessment, view feedback and allocated grades. For Themes 2 to 6 , the students were directed to an external site (Northstar Digital Literacy) [5]. The student could take a public version of a short assessment and receive a report on their skill level for basic computer skills. The generated report provided the student with information on skills to improve. Students could self-select relevant links to resources for further learning in areas that were identified as deficient.

The librarians developed a 'private link' to the module. The nursing academic team then embedded the private link in four first-year core subjects. As the link was private, the discipline librarian could monitor the overall student engagement and student participation in the modules.

\subsection{Analysis of Engagement}

A number of total views for each theme and the number of views across the academic year were collected to analyse student engagement. For this program, the student orientation week runs mid-February, whilst the academic year spans from March to the end of November. Therefore, data presented in this study spans the period from January 2020 to April 12, 2021, noting that during January 2021, the nursing academic team accessed the resource to review the modules.

\section{Results}

The module was completed on the $22^{\text {nd }}$ of January 2020. In 2020, the course enrolled 160 first-year students. In 2021, the course enrolled 164 first-year students.

\subsection{Screening Tool}

Although several tools were considered as means of identifying students at risk of low digital skill literacy, it was concluded that the implementation of the tool into curriculum structure would be complex as none of the diagnostic tools were adaptive enough to facilitate specific referral of the student to a set of resources needed to address the student's individual needs. There was also the issue of non-completion, how students responded to questions and what impact this would have on students in terms of time needed to complete the self-assessment. There was also the issue of where the diagnostic tool would be implemented so to avoid duplication. Furthermore, as the tool needed to be completed before starting the program, there was also an issue regarding whether a student with poor digital literacy skills would have the necessary skills to access and 
complete an online test without help. For this last reason, it was decided that the screening tool will not be implemented. Instead, each academic will promote the module to students through voluntary, self-directed engagement driven by adult learning principles [6]. The academic team would promote modules before any activity/assessment that required specific digital skills for successful completion. In addition, the liaison librarian would promote the module during student orientation week, which occurs one week before students commenced studies

\subsection{Engagement with the Module}

As the module was embedded in the LMS and the library organized private link access for nursing students, it was possible to track student engagement. Table 1 presents the total number of views for each module. Figure 1 shows the number of views since the module's implementation to the $12^{\text {th }}$ of April 2021.

Table 1. The number of total views of individual module themes since module implementation.

\begin{tabular}{lc}
\multicolumn{1}{c}{ Theme } & Number of views \\
\hline Digital Literacy Module & 724 \\
Theme 1: Using a learning management system & 143 \\
Theme 2: Basic computer skills & 103 \\
Theme 3: Internet basics & 69 \\
Theme 4: Using email & 50 \\
Theme 5: Microsoft Word & 60 \\
Theme 6: Microsoft PowerPoint & 45 \\
Theme 7: Using the library & 85 \\
Feedback & 0 \\
\hline
\end{tabular}

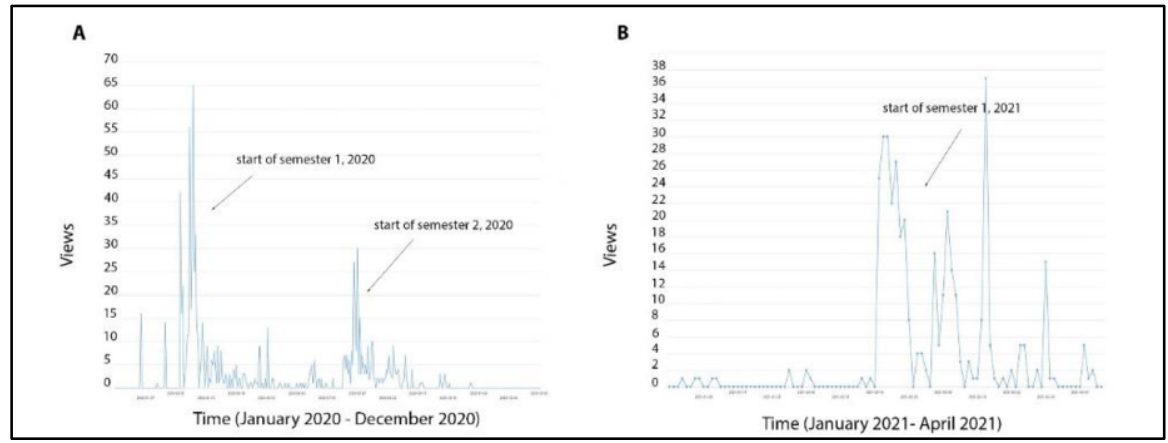

Figure 1. The distribution of the number of times students viewed the Digital Literacy modules since implementation. A) During 2020; B) Since January 2021.

\section{Discussion}

The initial project brief aimed to identify students with low digital literacy skills so that such deficit can be corrected and not transferred into their registered nurse practice, negatively impacting patient outcomes [1]. The idea to screen all students was abandoned as this could not be achieved in terms of sustainability and student tracking. Instead, the model had to rely on active promotion by the nursing academic team and discipline 
librarians. Another challenge that the team encountered was that during the 'storming' of ideas, there were substantial differences between what the nursing academics thought was required and what the academic skills unit and library representatives thought was needed. It took some time to recognize that building more sophisticated digital literacy skills rested on addressing the coalface issues rather than implementing the module with a higher degree of complexity that made assumptions on the existing level of digital literacy. The team considered this to be the next step in scaffolding digital literacy skills in the nursing program. As ideas evolved, the team experienced attrition from the group whereby members with specific interests pulled out as they felt that their expertise was not required.

Data obtained so far suggests that students have engaged most with the module with Theme 1, which is focused on digital literacy needed to navigate the LMS used in the course and WIL. This reflects the need of students to use this platform daily to manage their nursing studies and WIL. This was followed by basic computer skills (Theme 2) and using the library (Theme 6). The data does not tell us which students have accessed the resources, whether each view was attributable to a different student, or if the same subpopulation of the student cohort continuously engaged with the source to improve their digital literacy. It is noted that students left no feedback on the module. This may reflect being time-poor, not understanding the importance of providing feedback, or how this module is scaffolded into formal assessment taking place within the course, whereby course assessment completion depends on the digital literacy skills. The next step in this module is to increase student engagement on adult learning principles [6] and build the complexity of digital literacy skills to reflect the increasing needs of healthcare environments, including informatics. More work is planned on engaging with the student cohort to obtain feedback on the modules and how this can be improved to meet their needs as they transition to nursing practice.

\section{Conclusion}

Addressing nursing students' deficits in digital literacy skills during university study is an intervention that may facilitate nursing student timely progression through their studies and better transition to nursing practice in digitally-driven healthcare environments. The model reported here is relatively inexpensive, transferable to any settings where a library exists and permits the healthcare student/staff to engage in their own time and privacy.

\section{References}

[1] Brown J, Morgan A, Mason J, Pope N, Bosco A. Student nurses' digital literacy levels: Lessons for curricula. CIN: Computers, Informatics, Nursing, 38 (2020), 451-458.

[2] Skov A. The digital competence wheel. https://digital-competence.eu last accessed on 2021-05-06

[3] Karnoe A, Furstrand D, Christensen KB, Norgaard O, Kayser L. Assessing competencies needed to engage with digital health services: Development of the eHealth literacy assessment toolkit. J Med Internet Res 2018;20(5):e178 doi: 10.2196/jmir.8347

[4] All Aboard. Digital skills in higher education. https://www.allaboardhe.ie/ last accessed on 2021-05-06

[5] Northstar Digital Literacy. https://www.digitalliteracyassessment.org/ last accessed 2021-05-04

[6] Merriam SB, Bierema LL. (2013). Adult learning: Linking theory and practice. Jossey-Bass. 2013. 